ISSN: 1410-8917

Jurnal Kimia -Sains \& Aplikasi

e-ISSN: 2597-9914

\section{Jurnal Kimia Sains dan Aplikasi} Journal of Scientific and Applied Chemistry

Journal homepage: http://ejournal.undip.ac.id/index.php/ksa

\title{
Effect of Phosphate Addition and Exposure of Micro Waves on Comparatives Ca/F in Gipsum Waste: Preliminary Study of Hydroxyappatite Synthesis (HAp) from Ceramics Gypsum Industry Waste
}

\author{
Dewantoro $^{\mathrm{a},{ }^{*},}$, Margareta Novian Cahyanti ${ }^{a}$, dan Sri Hartini ${ }^{\text {a }}$ \\ a Program Studi Kimia, Fakultas Sains dan Matematika, Universitas Kristen Satya Wacana, Salatiga, Indonesia \\ * Corresponding author:652013046@student.uksw.edu \\ https://doi.org/10.14710/jksa.21.4.218-223
}

\section{Article Info}

Article history:

Received: 8 August 2018 Revised: 25 October 2018 Accepted: 26 October 2018 Online: 31 October 2018

Keywords:

hydroksapatit (HAp); gypsum; hydrothermal method; Atomic Absorption Spectrometer (AAS); Fourier Transform Infrared (FTIR); X-Ray Diffraction (XRD)

Kata Kunci: hidroksiapatit (Hap); gipsum; hidrotermal; Atomic Absorption Spectrometer (AAS); Fourier Transform Infra Red (FTIR) dan X-Ray Diffraction (XRD)

\section{Abstract}

This study aims to conduct an initial study of hydroxyapatite synthesis from ceramic gypsum waste. The parameters of the synthesis process carried out were variations in the time of the hydrothermal process namely 10, 20, 30, 40 and 50 minutes. The time variation was studied to study the effect of time on the hydroxyapatite character of gypsum waste. The initial synthesis process was conducted by looking at the comparison of Phosphate and Calcium levels in gypsum. In this study the results of the highest Phosphate levels obtained were $0.607 \%$ in the $10^{\text {th }}$ minute, while the largest Calcium levels were obtained in the $30^{\text {th }}$ minute which was $0.171 \%$. The treatment in the $30^{\text {th }}$ minute gave the most optimal difference in effect which was 0.413 . FTIR results showed the emergence of hydroxyapatite peaks namely $-\mathrm{OH}, \mathrm{PO}_{4}{ }^{3-}$ and $\mathrm{Ca}-\mathrm{O}$, as well as the increase in the intensity of the peak of gypsum powder before treatment and after treatment. While the XRD results strengthened the presence of hydroxyapatite in gypsum with the presence of high peaks at $2 \theta=31.08^{\circ} ; 32.14^{\circ}$ and $33.45^{\circ}$ respectively which indicated the presence of hydroxyapatite. While the main impurities in the synthesized hydroxyapatite are carbonates identified from FTIR results.

\footnotetext{
Abstrak

Penelitian ini bertujuan untuk melakukan studi awal sintesis hidroksiapatit dari limbah gipsum keramik. Parameter proses sintesis yang dilakukan adalah variasi waktu proses hidrotermal yaitu 10, 20, 30, 40 dan 50 menit. Variasi waktu dikaji untuk mempelajari pengaruh waktu terhadap karakter hidroksiapatit limbah gipsum. Proses sintesis awal dilakukan dengan melihat perbandingan kadar Fosfat dan Kalsium dalam gipsum. Dalam penelitian ini hasil kadar Fosfat yang didapat terbesar adalah $0,607 \%$ pada menit ke 10, sedangkan kadar Kalsium terbesar didapat pada menit ke-30 yaitu $0,171 \%$. Perlakuan pada menit ke-30 memberikan pengaruh beda nyata yang paling optimal yaitu 0,413. Hasil FTIR menunjukkan munculnya puncak-puncak hidroksiapatit yaitu $\mathrm{OH}, \mathrm{PO}_{4}{ }^{3-}$ dan $\mathrm{Ca}-\mathrm{O}$, serta terjadinya kenaikan intensitas puncak serbuk gipsum sebelum perlakuan dan setelah perlakuan. Sementara hasil XRD memperkuat adanya hidroksiapatit dalam gipsum dengan adanya puncak-puncak tinggi pada $2 \theta=31,08^{\circ}$; $32,14^{\circ}$ dan $33,45^{\circ}$ secara berurutan yang menunjukkan adanya hidroksiapatit. Sementara pengotor utama dalam hidroksiapatit hasil sintesis adalah karbonat yang diidentifikasi dari hasil FTIR.
} 


\section{Pendahuluan}

Kebutuhan masyarakat akan keramik meningkat 1015 persen dengan volume mencapai 385-402 juta $\mathrm{m}^{2}$ pada tahun 2016. Peningkatan permintaan keramik dalam masyarakat adalah guna renovasi bangunan, aksesories rumah, dan properti yang lainnya. Semakin meningkatnya keramik yang diproduksi, maka semakin banyak pula limbah yang dihasilkan. Gipsum adalah salah satu limbah yang dihasilkan dalam produksi keramik. Gipsum adalah bentuk hemihidrat dari kalsium sulfat dihidrat, dengan rumus kimia $\left(\mathrm{CaSO}_{4}\right)_{2} \mathrm{H}_{2} \mathrm{O}$ [1]. Gipsum merupakan masa yang padat dan berwarna abu-abu, merah atau coklat. warna tersebut disebabkan adanya zat lain seperti tanah liat, oksidasi besi, anhidrat, karbokhidrat, sedikit $\mathrm{SiO}_{2}$ atau oksida logam lain.

Menurut Surya [1], secara umum gipsum memiliki komposisi kimia sebagai berikut: $\mathrm{Ca}(23,28 \%), \mathrm{H}$ $(2,34 \%), \mathrm{CaO}(32,57 \%), \mathrm{H}_{2} \mathrm{O}(20,93 \%), \mathrm{S}(18,62)$. Menurut Ardhiyanto dkk. [2], komposisi dalam gipsum dari limbah PT. Petrokimia Gresik sebagai berikut: $\mathrm{SiO}_{2}(2,4 \%), \mathrm{Fe}_{2} \mathrm{O}_{3}$ (0,07\%), $\mathrm{CaO}(52,39 \%), \mathrm{P}_{2} \mathrm{O}_{5}(0,85 \%), \mathrm{SO}_{3}(43,59 \%), \mathrm{TiO}_{2}$ $(0,08 \%), \mathrm{CuO}(0,03 \%), \mathrm{SrO}(0,45 \%), \mathrm{Yb}_{2} \mathrm{O}_{3}(0,14 \%)$. Dari data tersebut, kandungan yang cukup besar dalam gipsum adalah Ca dan CaO. Menurut Nayak [3] komponen utama penyusun HAp adalah kalsium dan fosfat dengan rumus molekul $\mathrm{Ca}_{10}\left(\mathrm{PO}_{4}\right)_{6}(\mathrm{OH})_{2}$. Kalsium dan fosfat merupakan komponen utama mineral pada tulang dan gigi. Untuk memperoleh material substitusi tulang dan gigi yang tepat dengan menggunakan modifikasi senyawa kalsium dan fosfat, yaitu dengan cara mencampurkan prekursor kalsium dan fosfat melalui proses sintesis [3]. Hal ini tentu dapat dijadikan sebagai titik terang untuk memanfaatkan gipsum sebagai bahan dasar sintesis pembuatan biokeramik Hidroksiapatit (HAp) guna mengurangi limbah gipsum.

Beberapa penelitian tentang hidroksiapatit (HAp) antara lain oleh Sedyono dan Tontowi [4] yang memanfaatkan gipsum alami dari Kulon Progo dengan proses dan karakterisasi FTIR dan penelitian HAp oleh Wadu $d k k$. [5] yang menggunakan kerabang telur ayam untuk mendapatkan HAp. Sementara Puspa dan Asmi [6] menggunakan tulang sapi untuk menghasilkan HAp. Mahreni $d k k$. [7] mengatakan sudah banyak penelitian tentang HAp alami, akan tetapi di Indonesia masih menggunakan HAp sintetis yang diimpor dari luar negeri. Menurut Kalita dan Verma [8], sintesis hidroksiapatit dengan microwave memiliki beberapa kelebihan yaitu waktu sintesis yang lebih singkat, pemanasan yang teratur, reaksi yang cepat, mudah diproduksi, distribusi partikel yang miring, memiliki yield tinggi, kemurnian tinggi dan efisiensi transformasi energi dan tanpa pemanasan volume. Berdasarkan latarbelakang yang ada, penelitian ini bertujuan untuk menghasilkan hidroksiapatit (HAp) dari limbah gipsum dengan metode hidrotermal dan karakteristik menggunakan Atomic Absorption Spectrometer(AAS), Fourier Transform Infra Red
(FTIR) dan X-Ray Diffraction (XRD) untuk menghasilkan hidroksiapatit yang baik.

\section{Bahan dan Metode}

\subsection{Alat dan Bahan}

Bahan yang digunakan adalah limbah gipsum, sedangkan bahan kima yang digunakan adalah ammonium dihydrogen phosphate (ADP), amonium molibdat, $\mathrm{H}_{2} \mathrm{SO}_{4}$, asam askorbat, $\mathrm{HNO}_{3}, \mathrm{HCl}_{\text {pekat }}$ dan aquades. Piranti yang digunakan antara lain blender, neraca analitik, glass beaker, gelas labu, spatula, ayakan, cawan petri, pipet, magnetic stirrer, kertas saring, kertas $\mathrm{PH}$, Spektrofotometer UV-Vis, Atomic Absorption Spectrometer (AAS), microwave, Fourier Transform InfraRed (FTIR) Shimadzu IRPrestige-21 dan XRD X-Ray Diffraction (XRD) Bruker Advence 8.

\subsection{Metode}

\subsubsection{Sintesis Limbah Gypsum [4].}

Sebanyak 2,5 gr serbuk gypsum dilarutkan ke dalam $20 \mathrm{~mL}$ larutan ADP dan dihomogenkan. Larutan dimasukkan ke dalam microwave dan dipanaskan pada suhu $94^{\circ} \mathrm{C}$ selama 10, 20, 30, 40 dan 50 menit. Larutan kemudian dicuci dengan aquades dan disaring. Larutan kemudian dikeringkan dengan microwave dengan suhu $40^{\circ} \mathrm{C}$ selama 4 jam.

\subsubsection{Penentuan Kadar Fosfat dengan alat Spektrofotometer UV-Vis [9]}

Pembuatan Reagen PB Amonium molibdat ditimbang sebanyak $1,5 \mathrm{~g}$, dilarutkan dalam $30 \mathrm{~mL}$ akuades, dipanaskan pada suhu $60^{\circ} \mathrm{C}$, disaring dan didinginkan. Ditambahkan $\mathrm{H}_{2} \mathrm{SO}_{4}$ sebanyak $3,42 \mathrm{~mL}$, digenapkan hingga $100 \mathrm{~mL}$ dengan akuades. Reagen PC dibuat dengan cara asam askorbat menimbang sebanyak 0,1 g, dan dilarutkan dalam $25 \mathrm{~mL}$ akuades. Setelah itu pembuatan kurva standar. Larutan standar diambil sebanyak 0,$1 ; 0,2 ; 0,3 ; 0,4 ; 0,5 ; 0,6 ; 0,7 ; 0,8 ; 0,9 ; 1,0 \mathrm{~mL}$, masing-masing ditambahkan akuades agar totalnya menjadi $2 \mathrm{~mL}$, ditambahkan $1 \mathrm{~mL}$ reagen $\mathrm{PB}$ dan $0,4 \mathrm{~mL}$ reagen $\mathrm{PC}$, lalu diinkubasi selama 15 menit, diukur pada $\lambda$ $650 \mathrm{~nm}$.

Untuk menentukan Kadar Fosfat Sampel (HAp) adalah dengan cara serbuk HAp ditimbang sebanyak 2,5g, dilarutkan dalam $25 \mathrm{~mL}$ larutan campuran $\mathrm{HNO}_{3}: \mathrm{H}_{2} \mathrm{O}_{2}$ (7:3) (v:v), lalu dipanaskan pada suhu $150^{\circ} \mathrm{C}$, dinginkan pada suhu ruang. Diambil $2 \mathrm{~mL}$ larutan sampel, ditambahkan reagen $\mathrm{PB}$ ditambahkan sebanyak $2 \mathrm{~mL}$ dan ditambahkan 0,4 $\mathrm{mL}$ reagen PC. Diinkubasi selama 15 menit. Kadar Kalsium ditentukan dengan metode AAS [10]. Sebanyak $1 \mathrm{~g}$ serbuk gipsum ditambahkan kedalam

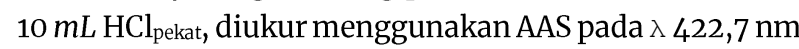
[4]. Hasil terbaik yang didapatkan dalam penentuan kadar fosfat dan kadar kalsium kemudian dikarakterisasi menggunakan FTIR dan XRD. 


\section{Hasil dan Pembahasan}

\subsection{Variasi waktu pemanasan}

Di bawah ini adalah hasil rata-rata yield yang diperoleh dalam limbah gipsum keramik dengan 5 perlakuan 5 ulangan.

Tabel 1. Prosentase rendemen serbuk gipsum dengan variasi waktu pemanasan

\begin{tabular}{|c|c|c|c|c|c|}
\hline Perlakuan & $\begin{array}{c}10 \\
\text { Menit }\end{array}$ & $\begin{array}{c}20 \\
\text { Menit }\end{array}$ & $\begin{array}{c}30 \\
\text { Menit }\end{array}$ & $\begin{array}{c}40 \\
\text { Menit }\end{array}$ & $\begin{array}{c}50 \\
\text { Menit } \\
\end{array}$ \\
\hline $\bar{x} \pm \mathrm{SE}$ & $\begin{array}{l}73,11 \pm \\
0.1697\end{array}$ & $\begin{array}{l}85,32 \pm \\
0.0632\end{array}$ & $\begin{array}{c}82,62 \pm \\
0.0921\end{array}$ & $\begin{array}{l}82,54 \pm \\
0.0669\end{array}$ & $\begin{array}{l}96,01 \pm \\
0.0829\end{array}$ \\
\hline
\end{tabular}

Tabel 1 menunjukkan bahwa yield mengalami kenaikan sesuai peningkatan waktu analisis dan paling besar pada variasi waktu 50 menit yaitu 96,01\% (w/w). Hal ini sesuai dengan penelitian Kalita dan Verma [8], bahwa sintesis dengan microwave memiliki yield relatif tinggi. Sintesis dengan pemanasan microwave merupakan proses sintesis tanpa menghasilkan produk padatan sampingan. Pemanasan microwave berbeda dari pemanasan konvensional, dengan cara, bahwa panas dihasilkan secara internal di dalam material bukan berasal dari sumber pemanas eksternal dan transfer radiasi selanjutnya. Pembentukan HAp terjadi dalam suasana basa dengan sejumlah asam dan sejumlah molekul air

\section{2. kadar fosfat $\mathrm{mg} / \mathrm{g}$}

Di bawah ini adalah hasil rata-rata kadar fosfat yang diperoleh dalam limbah gipsum keramik dengan 5 perlakuan 5 ulangan.

Tabel 2. Prosentase kadar fosfat (mg/g)

\begin{tabular}{lccccc}
\hline \multirow{2}{*}{ Perlakuan } & 10 & 20 & 30 & 40 & 50 \\
& Menit & Menit & Menit & Menit & Menit \\
\hline \multirow{3}{*}{$\begin{array}{l}\text { X SE } \\
\end{array}$} & 0.60682 & 0.51343 & 0.41714 & 0.38914 & 0.38314 \\
& \pm & \pm & \pm & \pm & \pm \\
& 0.0016 & 0.0024 & 0.0013 & 0.0001 & 0.0001 \\
\hline
\end{tabular}

Hasil kadar fosfat yang didapat dari limbah gipsum dengan menggunakan proses hidrotermal tertinggi di tunjukkan pada menit ke-10 yaitu 0,607\% (mg/g). Semakin lama proses yang diberikan pada sampel mengakibatkan pernurunan nilal kadar fosfat yang didapatkan. Hal ini dibuktikan dengan hasil pada Tabel 2 di mana semakin lama waktu yang diberikan makan semakin menurun kadar fosfat yang akan didapat. Penurunan kadar fosfat dalam penelitian ini disebabkan oleh adanya pengaruh panas yang diberikan oleh microwave. Suhu panas disini berperan sangat penting dalam pembentukan fosfat, di mana ketika fosfat berada dalam suhu panas yang cukup lama, maka fosfat akan mengalami kerusakan karakter. Kadar fosfat yang besar dibutuhkan dalam penelitian ini karena ketika diaplikasikan dalam pasta gigi maka akan semakin maksimal dalam mencegah lubang pada gigi serta karies pada gigi. Batas maksimal kandungan fosfat dalam pasta gigi yang diizinkan di Indonesia adalah $0.15 \%$, hal ini berarti dalam penelitian ini kadar fosfat yang didapatkan masih mendekati dari batas maksimal.

\subsection{Kadar Kalsium}

Di bawah ini adalah hasil rata-rata kadar kalsium yang diperoleh dalam limbah gipsum keramik dengan 5 perlakuan 5 ulangan.

Tabel 3. Prosentase kadar kalsium (mg/g)

\begin{tabular}{cccccc}
\hline Perlakuan & 10 Menit & 20 Menit & $\begin{array}{c}30 \\
\text { Menit }\end{array}$ & $\begin{array}{c}40 \\
\text { Menit }\end{array}$ & $\begin{array}{c}50 \\
\text { Menit }\end{array}$ \\
\hline \multirow{2}{*}{ \pm SE } & $0.1338 \pm$ & 0.14594 & $0.1712 \pm$ & $0.1553 \pm$ & $0.1623 \pm$ \\
& 0.0074 & \pm 0.0083 & 0.0095 & 0.0087 & 0.0091 \\
\hline
\end{tabular}

Penetapan kadar kalsium dapat dilakukan dengan beberapa metode, di antaranya adalah dengan metode SSA [11], gravimetri [10] dan kompleksometri [12]. Dalam penelitian ini metode yang digunakan adalah SSA. Metode SSA dipakai dalam penelitian ini karena kelebihannya yaitu hasil yang didapat spesifik dari batas deteksi sampel yang rendah. Kadar Ca maksimum ditunjukkan pada waktu pemanasan 30 menit yaitu $0.1712 \%$ (mg/g). Menurut Alfian [11] kalsium dan fosfat pada kondisi tertentu akan bereaksi dan membentuk dikalsium fosfat, kalsium akan terpisah dengan fosfat dan membentuk kalsium karbonat apabila ada suhu yang terlalu panas.

\subsection{Kadar Kalsium/Fostat(Ca/F)}

Di bawah ini adalah hasil rata-rata perbandingan kadar kalsium dibagi dengan kadar fosfat yang diperoleh dalam limbah gipsum keramik dengan 5 perlakuan 5 ulangan.

\section{Tabel 4. Prosentase kadar Kalsium/Fostat (Ca/F)}

\begin{tabular}{|c|c|c|c|c|c|}
\hline $\begin{array}{l}\text { Perla } \\
\text { kuan }\end{array}$ & 10 Menit & 20 Menit & 30 Menit & 40 Menit & 50 Menit \\
\hline $\begin{array}{c}\bar{x} \pm \mathrm{SE} \\
\mathrm{W}= \\
0,084 \\
28\end{array}$ & $\begin{array}{c}0.22159 \pm \\
0.1134 \\
\text { (a) }\end{array}$ & $\begin{array}{c}0.28677 \pm \\
0.1512 \\
\text { (b) }\end{array}$ & $\begin{array}{c}0.41270 \pm \\
0.2308 \\
\text { (c) }\end{array}$ & $\begin{array}{c}0.39909 \pm \\
0.2224 \\
\text { (c) }\end{array}$ & $\begin{array}{c}0.42352 \pm \\
0.2370 \\
\text { (c) }\end{array}$ \\
\hline
\end{tabular}

Data peningkatan kadar kalsium/fosfat dianalisis menggunakan racangan dasar Rancangan Acak Kelompok(RAK). Pengujian antar perlakuan digunaan uji Beda Nyata Jujur (BNJ) dengan tingkat kebermaknaan 5\%. Dari hasil analisis data yang diperoleh, maka mulai waktu pemanasan 30 menit memberikan hasil yang berbeda nyata.

Dari hasil pada tabel 4 dapat digambarkan seperti dibawah ini: 


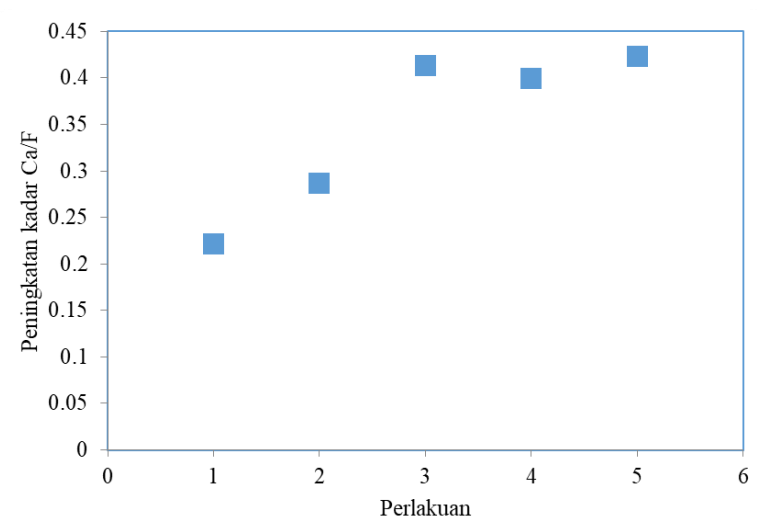

Gambar 1. Grafik peningkatan kadar Ca / F.

Sumbu X merupakan perlakuan yang diberikan pada sampel gipsum, sementara sumbu Y merupakan peningkatan kadar yang dihasilkan oleh sampel gipsum ini. Dapat dilihat pada perlakuan 3 memberikan hasil yang paling berbeda, hal ini ditunjukkan pada gambar perlakuan 3 menunjukkan puncak paling tinggi.

\subsection{Hasil FTIR Serbuk Gypsum}

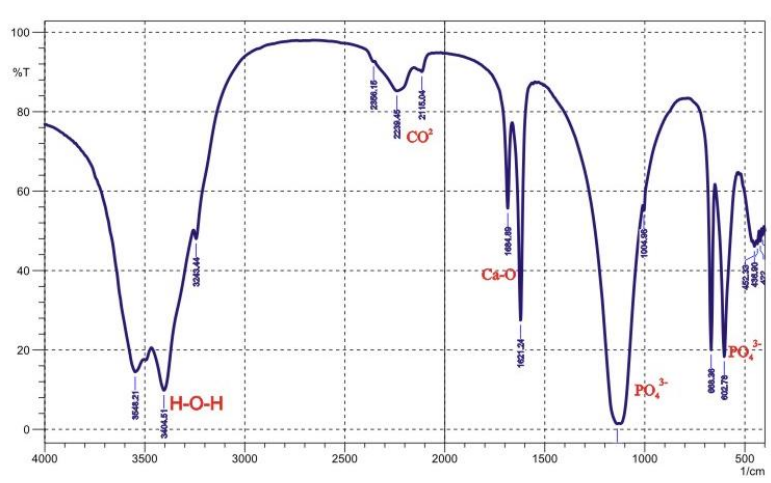

Gambar 2. Spektra FTIR serbuk gypsum yang belum ditambahkan perlakuan pemanasan dengan microwave

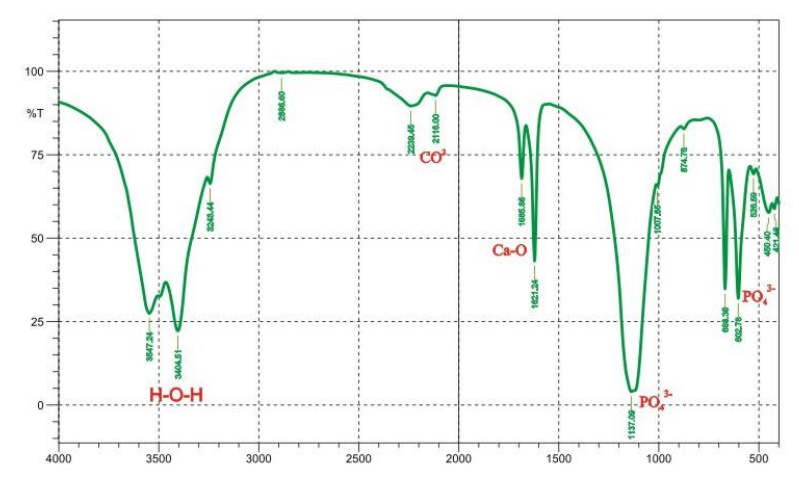

Gambar 3. Spektra FTIR serbuk gypsum yang sudah ditiambahkan perlakuan pemanasan dengan microwave selama 30 menit.

Gambar 2 dan 3 menunjukkan pola-pola FTIR yang tidak jauh berbeda sebelum perlakuan dan setelah perlakuan, hal ini dapat dilihat pada peak-peak tertentu yang mengalami sedikit kenaikan intensitas. Dari sini diyakini bahwa serbuk Gypsum mengandung Hidroksiapatit, walaupun masih dalam skala yang kecil.
Suatu sampel dapat dikatakan mengandung hidroksiapatit apabila adanya ikatan senyawa hidrogen ($\mathrm{OH})$, ikatan gugus fosfat $\left(\mathrm{PO}_{4^{3-}}\right)$, dan gugus fungsi Ca-O.

Spektra inframerah yang menunjukkan adanya ikatan molekul hidrogen terjadi pada bilangan gelombang 3412,08 $\mathrm{cm}^{-1}$ dan $3145,90 \mathrm{~cm}^{-1}$ yang ditandai adanya gugus fungsi $\mathrm{H}-\mathrm{O}-\mathrm{H}$ [13]. Sedangkan menurut Pattanayak $d k k$. [14] ikatan $\mathrm{OH}$ terdapat pada gelombang $3400 \mathrm{~cm}^{-1}$ dan $630 \mathrm{~cm}^{-1}$. Gambar 2 dan 3 menunjukkan adanya gelombang yang cukup tinggi pada bilangan $3404.51 \mathrm{~cm}^{-1}$.

Ikatan gugus fosfat $\left(\mathrm{PO}_{4^{3-}}\right)$ merupakan intensitas yang paling tinggi nampak pada bilangan 526,59 $\mathrm{cm}^{-1}$; $602,78 \mathrm{~cm}^{-1}$, dan 1137,09 $\mathrm{cm}^{-1}$. Menurut Sasikumar dan Vijayaraghavan [13] intensitas yang paling tinggi merupakan ikatan gugus fosfat $\left(\mathrm{PO}_{4^{3-}}\right)$ yang ditandai dengan bending dan stretching dari $\mathrm{P}-\mathrm{O}$ yang terdapat pada bilangan gelombang $503,21 \mathrm{~cm}^{-1} ; 603,72 \mathrm{~cm}^{-1}$ dan $1026,13 \mathrm{~cm}^{-1}$. Sedangkan menurut Pattanayak $d k k$. [14] ikatan gugus fosfat $\left(\mathrm{PO}_{4^{3-}}\right)$ paling kuat dengan stretching terdapat pada bilangan interval gelombang $1000 \mathrm{~cm}^{-1}$ $1150 \mathrm{~cm}^{-1}$ dan medium pada bilangan gelombang $960 \mathrm{~cm}^{-}$ ${ }^{1}$. Untuk bending diamati pada $560 \mathrm{~cm}^{-1}-610 \mathrm{~cm}^{-1}$.

Gugus fungsi senyawa fase Ca-O menurut Pattanayak $d k k$. [14] ditemukan pada gelombang $1400 \mathrm{~cm}^{-}$ ${ }^{1}-1700 \mathrm{~cm}^{-1}$. Gugus fungsi senyawa fase Ca-O ditemukan dalam struktur ini yang ditandai pada gelombang 1621,24 $\mathrm{cm}^{-1}$ - 1685,86 $\mathrm{cm}^{-1}$. Menurut Felício-Fernandes dan Laranjeira [15] bilangan gelombang $2100-2300 \mathrm{~cm}^{-1}$ yang merupakan ikatan $\mathrm{CO}_{2}$, , memiliki intensitas yang sangat rendah yang diindikasikan berasal dari udara luar. Ikatan $\mathrm{CO} 2$ ditemukan dalam struktur ini yang muncul pada bilangan gelombang $2116,00 \mathrm{~cm}^{-1}$ dan $2239,45 \mathrm{~cm}^{-1}$.

\subsection{Hasil XRD Serbuk Gipsum}

Di bawah ini merupakan hasil uji XRD dengan sampel serbuk gypsum yang dilakukan berdasarkan hasil paling maksimal pada kelima perlakuan yang telah diberikan pada gypsum.

Tabel 5. Hasil XRD Serbuk Gipsum

\begin{tabular}{ccc}
\hline \multirow{2}{*}{ 2 Theta } & \multicolumn{2}{c}{ Intensitas } \\
\cline { 2 - 3 } & Tanpa Perlakuan & Perlakuan 30 menit \\
\hline 31.08 & 10381.36 & 32633.12 \\
32.14 & 6268.36 & 28231.12 \\
33.45 & 8738.36 & 31203.12 \\
\hline
\end{tabular}

Sampel gypsum yang dianalisis adalah sampel yang sudah diberi perlakuan pada menit ke-30, karena pada menit ke-30 ini memberikan hasil yang paling baik. Serta ditambah serbuk gypsum yang belum diberi tambahan perlakuan, hal ini di tujukan agar dapat dilihat kenaikan yang dihasilkan dari perlakuan yang diberikan. Dapat dilihat pada tabel 5, di mana pada gelombang yang mengindikasikan terdapatnya HAp terjadi peningkatan 
yang baik setelah diberi tambahan perlakuan pada sampel gypsum.

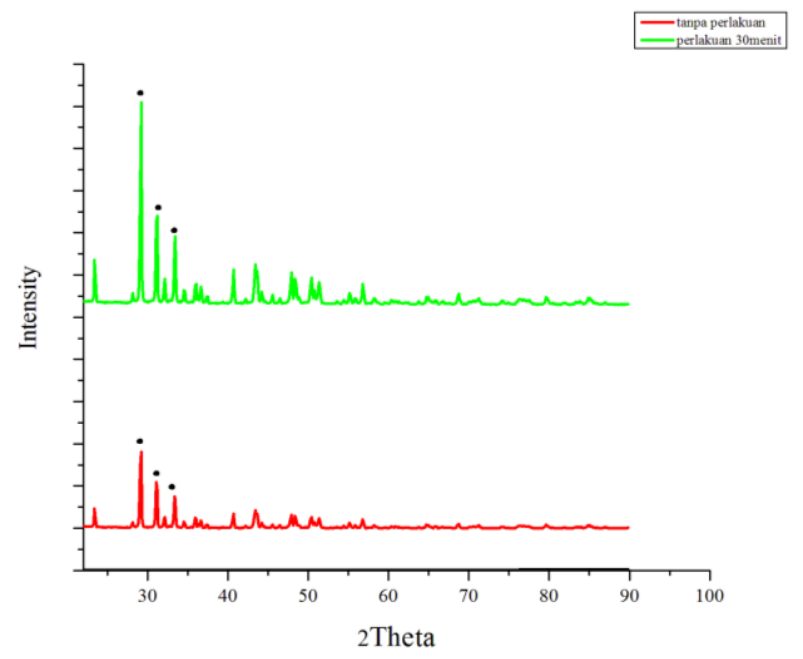

Gambar 4. Difraktogram XRD

Analisis dengan menggunakan metode difraksi sinar-X (XRD) sebagai tahap awal untukmengidentifikasi pembentukan fasa pada sampel serbuk gypsum dengan menggunakan metode hidrotermal dan perbandingan sebelum dilakukan perlakuan dan setelah dilakukan perlakuan. Hasil analisis uji XRD pada sampel serbuk gypsum menunjukkan kenaikan peak-peak intensitas setelah dilakukan pemanasan dengan microwave selama 30 menit. Hal ini dapat dilihat pada gambar 4 di mana pada intensitas; yang selalu mengalami kenaikan setelah adanya perlakuan yang dilakukan pada serbuk gypsum. Menurut El Boujaady $d k k$. [16], tiga puncak utama dari hidroksiapatit adalah pada $2 \theta=31-33$ secara berurutan. Dan hasil dari penelitian ini yaitu pada 20:31.08, 32.14 dan 33.45 secara berurutan. Dari hasil XRD didapatkan bahwa penambahan variasi waktu (30 menit) dapat meningkatkan kadar HAp dalam serbuk gypsum. Sebelumnya dalam penelitian tentang hidroksiapatit oleh Purwasasmita dan Gultom [17] menunjukkan hasil XRD yang sama yaitu terbentuknya puncak tertinggi pada pada $2 \ominus ; 31,77 ; 32,90$ dan 32,19 secara berurutan. Dengan semakin kuatnya hasil yang diperoleh serta hasil yang tidak meleset jauh dari hasil referensi, ini menunjukkan bahwa perlakuan yang ditambahkan pada serbuk gypsum sudah cukup akurat untuk menaikkan kandungan hidroksiapatit, walaupun kandungan yang didapatkan masih terlalu kecil

\section{Kesimpulan}

Hasil studi awal sintesis HAp limbah gipsum keramik adalah penambahan fosfat dalam sintesis hidroksiapatit menggunakan proses hidrotermal ini sangat memberikan hasil yang baik pada sampel limbah gypsum keramik. Di mana dengan adanya penambahan fosfat dalam sintesis dengan proses hidrotermal ini meningkatkan kandungan hidroksiapatit dalam sampel gypsum limbah keramik. Akan tetapi masih perlu dilakukan penelitan lebih lanjut guna mendapatkan hasil yang lebih baik lagi. Agar dapat dimanfaatkan limbah gypsum keramik ini untuk diaplikasikan dalam pasta gigi.

\section{Referensi}

[1] Ahmad Faathir Surya, Gypsum, Departemen Teknik Sipil, Universitas Indonesia, Jakarta

[2] Hengky Bowo Ardhiyanto, Yenny Yustisia, Amiyatun Naini, Sintesis dan karakterisasi Hidroksiapatit dari Limbah Dental GypsumTipe 2 sebagai Bahan Baku Bone Graft, in: FORKINAS VI FKG UNEJ, FKG Universitas Jember, Jember, 2016.

[3] Amit Kumar Nayak, Hydroxyapatite synthesis methodologies: an overview, International Journal of ChemTech Research, 2, 2, (2010) 903-907

[4] Joko Sedyono, Alva Edy Tontowi, Proses Sintesis dan Karakterisasi FTIR Hidroksiapatit dari Gipsum Alam Kulon Progo, Media Mesin, 9, 1, (2008) 6-12

[5] Imelda Wadu, Hartati Soetjipto, Margareta Novian Cahyanti, Sintesa dan Penentuan Kadar KalsiumFosfat Hidroksiapatit (HAp) dari Kerabang Telur Ayam, Jurnal Kimia dan Pendidikan Kimia, 3, 1, (2018) 1-5 http://dx.doi.org/10.20961/jkpk.v3i1.11860

[6] Ketut Adi Puspa, Dwi Asmi, Sintesis dan Karakterisasi Biokeramik Hidroksiapatit Bahan Tulang Sapi pada Suhu 800-1100, Jurnal Teori dan Aplikasi Fisika, 2, 2, (2014) 125-129

[7] Mahreni, Endang Sulistyowati, Saeful Sampe, Willyam Chandra, Pembuatan Hidroksi Apatit dari Kulit Telur, Prosiding Seminar Nasional Teknik Kimia "Kejuangan" 2012, Yogyakarta, (2012) C07-01

[8] Samar J. Kalita, Saurabh Verma, Nanocrystalline hydroxyapatite bioceramic using microwave radiation: Synthesis and characterization, Materials Science and Engineering: C, 30, 2, (2010) 295-303 https://doi.org/10.1016/j.msec.2009.11.007

[9] Pamela Doolitle, Ascorbic acid method for phosphorus determination, in, University of Wisconsin Madison, 2014.

[10] John Hendri, Wardana Wardana, Irwan Ginting Suka, Aspita Laila, Penentuan Kadar Ca dan Mg pada Hasil Demineralisasi Optimum Kulit Udang Windu (Penaeus monodon) secara Gravimetri dan Spektroskopi Serapan Atom, Jurnal Sains MIPA Universitas Lampung, 13, 12, (2007) 93-99

[11] Zul Alfian, Penentuan Kadar Unsur Kalsium (Ca2+) pada Susu Sapi Murni dan Susu Sapi di Pasaran dengan Metode Spektrofotometri Serapan Atom, Jurnal Sains Kimia, 8, 1, (2004) 26-28

[12] Zaib Hussain, Ammara Nazir, Umer Shafique, Muhammad Salman, Comparative study for the determination of metals in milk samples using flame-AAS and EDTA complexometric titration, Journal of Scientific Research, 40, 1, (2010) 1-6

[13] S Sasikumar, R Vijayaraghavan, Low temperature synthesis of nanocrystalline hydroxyapatite from egg shells by combustion method, Trends in Biomaterials \& Artificial Organs, 19, 2, (2006) 70-73

[14] Deepak K Pattanayak, P Divya, Sujal Upadhyay, RC Prasad, BT Rao, TR Rama Mohan, Synthesis and 
evaluation of hydroxyapatite ceramics, Trends in Biomaterials \& Artificial Organs, 18, 2, (2005) 87-92

[15] G Felício-Fernandes, Mauro Laranjeira, Calcium phosphate biomaterials from marine algae. Hydrothermal synthesis and characterisation, Quimica Nova, 23, 4, (2000) 441-446 https://doi.org/10.1590/s010040422000000400002

[16]H El Boujaady, M Mourabet, AEL Rhilassi, M Bennani-Ziatni, R El Hamri, A Taitai, Adsorption of a textile dye on synthesized calcium deficient hydroxyapatite (CDHAp): Kinetic and thermodynamic studies, Journal of Materials and Environmental Science, 7, 11, (2016) 4049-4063

[17] Bambang Sunendar Purwasasmita, Ramos Samuel Gultom, Sintesis dan karakterisasi serbuk hidroksiapatit skala sub-mikron menggunakan metode presipitasi, Jurnal Bionatura, 10, 2, (2008) 155-167 